\title{
Analysis of drill bit speed in bit-rock interaction with the use of numerical simulation methods
}

\author{
Lazizjon Toshniyozov ${ }^{1 *}$, and Muhriddin Mamatov ${ }^{1}$ \\ Tashkent State Technical University, Department of Mining Electromechanics, 2 University St., \\ 100095 Tashkent, Republic Uzbekistan
}

\begin{abstract}
Bit-rock interaction while drilling wells using numerical simulation methods is analyzed in the article. The effect of the location of the buttons relative to the destruction of the rock, the influence of the structure on the total speed of the drill bit was considered. The total bit velocity was investigated by comparing the results of modeling the operation of the industry bit and the optimized bit. Using methods of numerical modeling allowed creating an atmosphere of the drilling process in a computer environment, where the destruction of rock using a rock cutting tool was analyzed. Due to the pairwise positioning of the buttons in the optimized bit modeled in the ANSYS program, the number of buttons decreased by 13 pieces and the performance of the bit increased significantly. The optimized bit demonstrates more intense penetration into the rock and obvious fragmentation on the rock surface. A drill bit with a pair of buttons rotates more intensively and acts on the cross-sectional area of the rock with values greater than a bit with button of a conventional location. Rising values of the total velocity on the graph signal the dynamic movements of the rock cutting tool.
\end{abstract}

\section{Introduction}

The mining and metallurgical industry is one of the prevalent industries in many countries. At the present stage, it is characterized by intensive development of mineral deposits, which has gained predominant importance in the extraction of non-ferrous metal ores, gold, mining and chemical raw materials and building materials.

Drilling is one of the main processes of the mining industry, which averages $25-55 \%$ of the cost of mining. Well drilling is carried out with rock cutting tools, with the help of which rock is destroyed for drilling and blasting operations in quarries, as well as in the construction of deep wells in the oil and gas industry, well drilling in the coal industry and exploration. Drill bits are also widely used in the construction of bridges, tunnels and other facilities. In this regard, there is currently a shortage of high-quality and inexpensive tools for rock destruction on the world market.

The drill bit is one of the tools operating in very harsh conditions, under heavy loads of tens of tons and other indicators in a highly abrasive environment in which even hard-alloy rock cutting buttons reinforced with diamonds quickly wear out. Difficult working

\footnotetext{
* Corresponding author: 1toshniyozov@,tdtu.uz
} 
conditions drill bits face at the bottom require use of the highest quality and highly resistant materials in their designs.

The search for new, more effective modifications of drill bits continues, since the destruction of rocks during drilling is an unsteady process. This is due to a constant change in geological conditions, technical characteristics of drilling rigs, strength and abrasive properties of rocks, their intermittency along the depth of the well. At the same time, the drill bit as a mechanism that directly destroys the rock and forms the wellbore, is also structurally changed and improved.

The drilling process has two aspects: technical - development, design and manufacture of drilling rock cutting tools and technological - optimal choice of drilling tools in accordance with the physical-mechanical conditions of the bottom hole and determining optimal drilling modes: axial loads, tool rotational velocity and the amount of fluid supplied (air) into the bottom of the well. These issues currently remain unresolved, because bottom hole conditions differ by geological region. Therefore, not in all cases, the optimization of the choice of the drill bit will be effective, which equally applies to the process of optimizing drilling modes [1].

In turn, a particularly complex and expensive technology in the manufacture of drill bits, expensive equipment and materials lead to the high cost of drill bits (from 1 to 15 thousand US dollars), which relatively affect the cost of extracted minerals, vital for each state.

Intensification of the drilling process and reduction of its cost are possible due to the use of new, more effective rock cutting tools, the choice of a rational type and a more advanced technology for their development in specified mining conditions.

Over the past decades, scientists have made a great contribution to the development of the scientific foundations for creating new and improving existing rock-cutting drilling tools, and they were carried out mainly in two directions: the study of the stress-strain state of rocks when acting on half-planes and the study of the dynamics of rock-cutting tools. At the same time, there are unresolved problems caused by the lack of a connection between the conditions for idealizing rock properties and the working conditions of working bodies.

In recent years, on the development and improvement of the design of drill bits, the creation of new materials and technologies, designers are paying more and more attention to optimizing the designs and manufacturability of bits. As practice shows, only on a deterministic basis, i.e. based on the specified parameters of the geometry of the drilling tool, it is possible to solve the problems of optimization of both the geometric parameters of drilling rock cutting tools and the technological parameters of the drilling process of wells of various sizes.

Today's trend requires reducing the time for modernizing serial or developing new types of drill bits from several months to several weeks. This additionally requires a scientific approach to design optimization and the development of high-performance drill bits when drilling wells to reduce the cost of $1 \mathrm{~m}$ of drilling.

The causes of failure of the rock cutting tool are explained by the fact that it, like other technological equipment, has a certain relationship between the parts. With the bearing or pin axle fully operational, the stoppage of its operation can be caused by a breakdown of the buttons on the cones of the bits; roller cone splicing can occur when bearings are not working properly; the formation of cracks on the surface of the cone may impede the normal working functionality of other elements of the destructive tool; the abrasion of several buttons can also cause the driller to stop working and replace the bit.

Optimization, although in relative values of the considered values of certain criteria, makes it possible to optimize the generalized criterion for the selected tool size. Despite the fact that maximum efficiency can be achieved only through the implementation of interrelated comprehensive studies to improve the performance of the armament of the bit, 
their manufacturing technology, cones and crowns, sliding and rolling bodies, lubrication and face cleaning systems, a partial increase in the performance of individual elements can have a significant impact. The versatility and complexity of complex research requires many factors to be carefully studied by scientists. Practice shows that in order to achieve the optimal solution in the design of high-tech rock cutting tools, the use of theoretical and experimental methods in such complex tasks as studying the force effects that impact the stress-strain state of the face and bit elements, the choice of the shape of the buttons allows drilling certain rocks, the choice of pairs rolling and sliding, identifying clearances in bearings and eliminating them, assembling a bit with its components is not optimal methods in terms of speed and economy. It is clear that the cost of designing, developing bits for laboratory research or field experiments is not cheap. In addition, according to [2], any experiments to determine the optimal shape of the buttons in the field conditions are further complicated by a number of aspects - changing the drilling interval and the properties of intermittent rocks, fluctuations in the load and velocity, the intensity of cleaning from the sludge, the influence of the properties of the washing liquid and its effect a column in the well to separate particles from the bottom, etc.

Given all the above difficulties in creating optimal drill bits, modern science offers the use of computer modeling at the design stage of rock cutting tools so that both material resources and development time are saved. Using methods of numerical modeling allows creating an atmosphere of the drilling process in a computer environment, where one can analyze the destruction of rock using a rock cutting tool.

\section{Materials and methods}

An engineering software program ANSYS based on the finite element method was used as the main research tool. The program allows one to analyze the mechanical speed of a tricone bit when penetrating a rock.

The data for the simulation is set in the program after the input of the properties of the simulation objects. Certain assumptions are provided to simplify the calculation of the numerical model. For example, the bit was created in another CAD program and simplified as a whole solid body to import to Ansys, which allows saving time on simulation and using computer resources rationally. In addition, the following parameters are neglected: pressure, bottom temperature, fluid flow, re-fragmentation of rock fragments. Destruction of the rock is visualized by the removal of red elements upon reaching the strength threshold.

The simulation time in ANSYS explicit dynamics is set to 3 milliseconds, the angular velocity is $100 \mathrm{rpm}$ on the $\mathrm{X}$ axis and the axial load is $30 \mathrm{kN}$ along the $\mathrm{Y}$ axis. Remote displacement of the bit towards the rock with a value of $70 \mathrm{~mm}$ along the $\mathrm{Y}$ axis and 360 degrees rotation around its axis allows getting the rotational impact of the bit. The rock was fixed laterally so that it did not move during contact. Considering the experience with the program and the fact that the simulation process is very complex and computer resources are limited by the mesh parameters, the button body was set by default, the contacting tips of the buttons were $5 \mathrm{~mm}$ and the mesh value of the rock was set to $6 \mathrm{~mm}$. With decreasing mesh size, one can observe how the number of elements and nodes increases. It should be noted that the smaller the mesh value, the more accurate the results can be obtained in the program.

In Ansys for obtaining results, solution parameters were set. To calculate the mechanical drilling speed, the total velocity function is selected to see how the position of the buttons affects the speed of the bit.

In addition, for the simulation process, material properties were applied to the buttons, bit and rock that are shown in Table 1 . 
Table 1. Properties of the materials of the bit, buttons and rock.

\begin{tabular}{|c|c|c|c|}
\hline Name & Drill bit & Buttons & Rock \\
\hline Q-ty & 1 & 17 & 1 \\
\hline Shape & tricone & Vaulted button & Quadrangular \\
\hline Material & Stainless steel & Thungsten carbide & Limestone \\
\hline Density & $15600 \mathrm{~kg} \mathrm{~m}^{-3}$ & $7850 \mathrm{~kg} \mathrm{~m}^{-3}$ & $2700 \mathrm{~kg} \mathrm{~m}^{-3}$ \\
\hline Tensile strength & $4.6 \mathrm{E}+08 \mathrm{~Pa}$ & $4.45 \mathrm{E}+08 \mathrm{~Pa}$ & $4.0 \mathrm{e}+06 \mathrm{~Pa}$ \\
\hline Young's modulus & $2 \mathrm{E}+11 \mathrm{~Pa}$ & $6.34 \mathrm{E}+11 \mathrm{~Pa}$ & $3.7845 \mathrm{E}+10 \mathrm{~Pa}$ \\
\hline Poisson ratio & 0.3 & 0.21 & 0.3077 \\
\hline
\end{tabular}

\section{Study of bit-rock interaction}

In modeling, energy, momentum, and forces change over time. The main reason may be the fact that when a rock element is destroyed, contact between the button and the rock sharply occurs, and the parameters suddenly fall when the elements interacting with the cutting tool break. After that, when another button hits the rock, energy, momentum and strength increase rapidly.

In the process of interaction of the elements of the cone (buttons) with the surface of the rock, the kinetic energy of the destructive tool passes into the rock in the form of energy of mechanical shock. The kinetic energy indices indicate that when the speed changes, the energy fluctuates accordingly. The drilling speed is described by the average speed of the drill bit. The advancement of the drilling tool through the rock is provided through the shock-rotational stress that occurs when the rock strength increases and is characterized by the energy level. In addition to rock strength, a change in the physical and mechanical properties of the rock can also affect power. The power transmitted to the working body of the bit contributes to lowering the cone button to the face and interact with the rock.

When assessing the maximum stress that occurs when lowering the cone button to the bottom, it is necessary to determine the maximum linear velocity of the button developed during the rotation of the cone. Linear velocity is characterized by the rotational velocity of the drill string, the ratio of the diameter of the bit and the diameter of the cone on which the buttons are located. The essence of the process of movement of the cone at the moment of rolling consists in the rotation of the cone around the instantaneous center of rotation $O$ (Fig. 1). The cone in the process of rotation rests on the point $O$ and rotates around it.

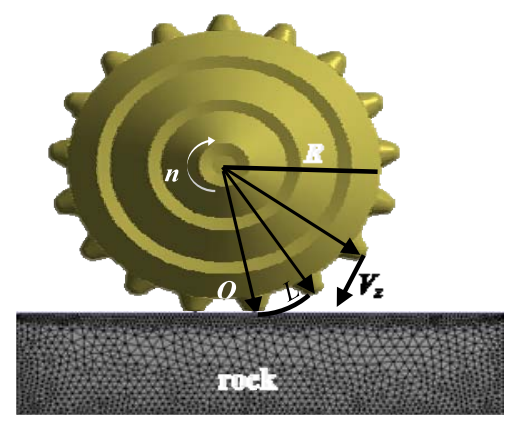

Fig. 1. Scheme for determining the drill bit speed in bit-rock interaction: $R$ is cone radius, m; $L$ is distance between the buttons, $\mathrm{m}$; $O$ is instantaneous center of rotation; $n$ is speed of rotation of the cone, $\mathrm{r} / \mathrm{s} ; V z$ is button velocity of contact with $\mathrm{rock}, \mathrm{m} / \mathrm{s}$. 
According to the laws of theoretical mechanics, under conditions of a big amount of buttons, the velocity of rotation of the cone relative to point $O$ can be expressed as follows [3]:

$$
V z=30 n_{r} \cdot \frac{D_{c} D_{b}}{2 D_{c}} \cdot \frac{S}{D_{c}}=15 n_{r} D_{b} \cdot \frac{\pi D_{c}}{D_{c} \kappa}=15 n_{r} D_{b} \cdot \frac{\pi}{\kappa},
$$

where $n_{r}$ is bit rotation frequency, $\mathrm{rpm} ; D_{b}$ is the diameter of the bit, $\mathrm{m} ; D_{c}$ is cone diameter, $\mathrm{m} ; S$ is distance between all the buttons of the cone in the projection plane perpendicular to the line of contact of the cone with the surface of the rock; $k$ is number of buttons of all rows of cone.

To determine the drilling speed for certain rocks with specific properties, the formula is used [4]:

$$
V_{b}=\frac{40 P_{a x} n_{r}}{P_{d} D_{b}^{2}}, \mathrm{~m} / \mathrm{h},
$$

where $P_{a x}$ is axial load on the bit, $\mathrm{N} ; P_{d}$ is an indicator of drillability.

\subsection{Ways to improve the rock cutting tool's performance}

The main factors affecting the efficiency and durability of a rock cutting tool when drilling according to rock characteristics include: dynamic (shock and vibration) impacts on the tool $[5,6]$; insufficient sealing of the main nodes of drill bits from the effects of flushing water and sludge $[7,8]$; as well as the organization and manufacturability of preventive maintenance [9].

These factors are widely studied and taken into account in the practice of designing and operating rock cutting tools. At present, everyone already understands how complicated the drilling and rock destruction processes are at the bottom of the well, and they realize how important the constructive model of the drilling tool plays in this $[10,11]$.

One of the most popular tools in modern drilling is the tricone drill bit. It refers to devices of the direct type, that is, crushes and removes the rock around its entire perimeter. Thus, the entire working area of the installation is developed, which increases its efficiency. Due to its high efficiency, tricone bits are used in drilling $75-85 \%$ of various wells.

We studied the efficiency of the rock destruction process when rolling the buttons of one cone of a tricone bit along the bottom and for analysis we selected two versions of such bits. The commercial bit used in production and our proposed version of the bit with a "pair" arrangement of buttons on the crown of the cone.

The paper analyzes the interaction of a rock cutting tool with rock during drilling using the ANSYS program, which operates on the basis of numerical simulation methods. Most studies conducted using the program and the finite element method have revealed a number of advantages and positive results. Many scientists [12 - 15] carried out experiments of one button in interaction with the rock, putting fundamental knowledge for subsequent studies, and only a few conducted computer experiments with PDC bits. It is shown that the integration of software packages used for the design of bits can contribute to the study of new designs and provide quick and efficient creation of rock cutting tools. Having studied the value of using the ANSYS program $[16,17]$ to analyze drilling processes and to achieve optimization of the geometry of cone rock cutting tools, one can rely on the program algorithms at a time when experimental research is expensive.

This comprehensive approach to the design of the bit optimizes, improves productivity, and accurately aligns the cutting structure, bit body, hydraulics and other characteristics of drilling processes. There are many engineering programs, each of which allows one to implement the design and performance characteristics of the bit, as well as related 
compromises for optimizing rock cutting tools. With the increasing demands of mining markets for low-cost products and processes that provide optimal performance, ANSYS is becoming an increasingly popular and widely used tool for designing drill bits.

Studying the world practice on designing rock cutting tools using the ANSYS program, it was revealed that the program was mainly used to optimize the design of PDC type drill bits. In this work, we investigated tricone drill bits with a diameter of $215.9 \mathrm{~mm}$ for drilling limestone with a strength of $f=8-10$ on the Protodiakonov scale.

\subsection{Analysis of the total velocity in the interaction of a industrial tricone bit with a rock in ANSYS Explicit Dynamics}

The model of the tricone bit is shown in Fig. 3. The properties of the materials of the bit, buttons, and rock, in this case limestone, often found in wells of quarries, are shown in Table 1. In addition, table 1 contains parameters such as compressive and tensile strength, Young's modulus and Poisson's ratio, which are necessary for analysis, are given in the database of the ANSYS program (Engineering data sources - Geomechanical materials Limestone). At the end of the data entry, the simulation starts to analyze the speed of the drill bit when the rock is subjected to shock-rotational movement.

The destruction of the rock at a high rate under the influence of the bit characterizes the mechanical drilling speed, which directly determines the efficiency of the rock cutting tool. The more intensively the rock is drilled with less energy for destruction, the more effective is the bit used in drilling operations.

In [18], the mechanical drilling speed of a diamond bit (PDC) is determined by using the Explicit Dynamics module of the ANSYS program. The performance of an optimized bit in this work is determined in a comparative analysis of the work of a industry bit with an optimized version. To analyze this experiment, that is, to optimize the speed of penetration of a tricone bit into the rock, the ANSYS Explicit dynamics module is used.

The simulation analysis process took about 26 hours. In Fig. 2 you can see how the rock is destroyed due to penetration into it, that is, the shock-rotational action of the bit's buttons. The destruction of the rock is explained by the factor that, due to the penetration of the elements of the bit into it, it loses its structural structure and reaches its ultimate strength. The simulation results of the industrial bit are shown in a linear graph (Fig. 3).

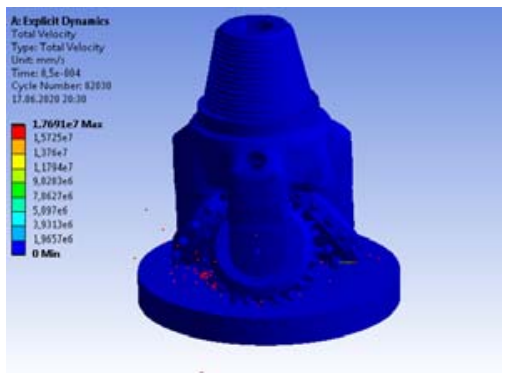

Fig. 2. The model of an industrial bit-rock interaction for the analysis of the total velocity.

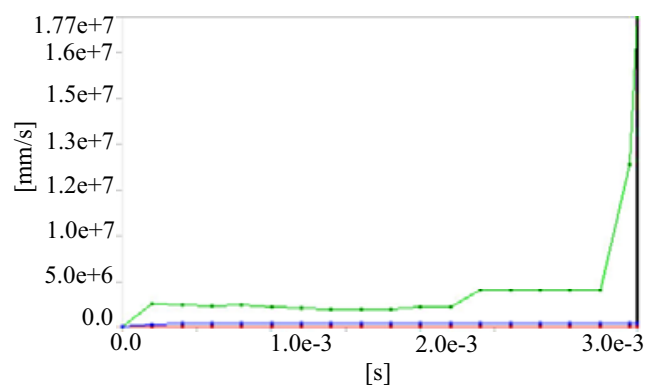

Fig. 3. Graph of change in total drill bit speed.

According to the graph (Fig. 3), it is clear that the speed of penetration of the industrial bit's buttons into the rock tends to run uniformly in the first half of the simulation and, starting from the second, a gradual increase in speed is observed. The development of intense speed is observed from the end of the second half, which means the beginning of the removal of fragments from the surface of the rock by the penetration of the buttons into 
it deeper and contributing to an increase in speed. The peak of speed can be seen in the final period of the simulation.

\section{Drill bit optimization}

After the analysis of the total bit speed of the commercial drill bit, an optimization process can be conducted. For this study, the optimization of the drill bit is based on design features, namely: the location of the buttons on the cones, which are vulnerable to wear faster than other crowns. The industrial bit has 42, 37, 37 buttons on three legs, respectively.

To demonstrate the relationship between the modified design and the penetration rate, numerous tests were carried out with a bit with various design features. The number of buttons was regulated from 30 to 45 pieces and their location also varied.

Based on the analysis of the tests obtained as a result of the simulation, the optimal design for the tricone bit was selected, which consists of 38,32,33 pieces of buttons. The optimized drill bit is modeled again using ANSYS Explicit Dynamic to measure its performance.

\subsection{Analysis of the total velocity in the interaction of the optimized tricone bit with rock in ANSYS Explicit Dynamics}

Parameter setting and analysis of the optimized bit is carried out similarly to the industrial one. After entering the necessary data, an analysis is carried out.

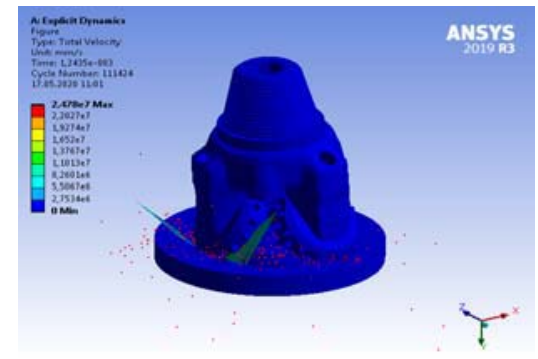

Fig. 4. Penetration of an optimized tricone bit into a rock when analyzing the total bit speed.

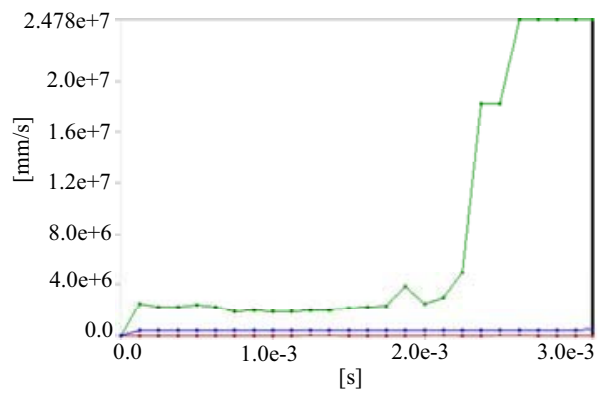

Fig. 5. Graph of changing the overall speed of the optimized drill bit.

In Fig. 4, mechanical fragmentation can be seen, that is, the tool is eats into the rock, and the rock under the influence of the tool is destroyed into small fragments, leaving cracks inside the remaining rock wall.

An analysis of the overall speed of the optimized tricone bit when interacting with the rock (Fig. 5) shows that a bit with a pair of buttons on the crowns moves faster than the cone of the commercial bit, and in a more aggressive oscillatory form. Starting from the second half of the simulation, the overall speed of the model develops intensively and reaches its peak at the end of the simulation period.

\section{Results and discussions}

As you know, drilling mid-hard and hard rocks requires a close arrangement of buttons on the crowns to reduce wear and increase the load on hard rock. Since the effect of the location of 
the buttons relative to the destruction of the rock was considered in the work, it was necessary to study the effect of the structure on the overall speed of the rock-cutting tool.

When analyzing the results of the industrially-used and new bits, it was revealed that the maximum total speed of the former as a result of analysis with an axial load of $30 \mathrm{kN}$, the angular speed of rotation of the bit $100 \mathrm{rpm}$ is $1770 \mathrm{~mm} / \mathrm{s}$, whereas for the new bit, it is $2480 \mathrm{~mm} / \mathrm{s}$. The arithmetic average of the total speed for the commercial bit is $290 \mathrm{~mm} / \mathrm{s}$, and the optimized bit has $410 \mathrm{~mm} / \mathrm{s}$. The results show a considerable increase in total drilling speed. A graph of the rate of penetration versus time for a production and optimized drill bit demonstrates the effects of structural changes on the penetration rate.

\section{Conclusions}

Due to the arrangement of the buttons in pairs in the new bit, the number of inserts is reduced, and the performance of the bit increased. The optimized bit has 38, 32, 33 pieces of buttons on the crowns of all three cones, 13 pieces fewer inserts than on the industriallyused bit. At the same time, the optimized bit demonstrates a more intense penetration into the rock and obvious fragmentation on the rock surface.

An optimized bit with a pair of buttons is rotated more intensively and acts on the crosssectional area of the rock with values greater than the inserts of the commercial bit. It is important to that rising values of the total speed on the graph signal the dynamic movements of the rock cutting tool.

This study was conducted as part of the research plan of innovative project of Tashkent State Technical University on the topic of "Development and testing of a new generation rock cutting tool for drilling wells" (State registration No. I-2016-2-25).

\section{References}

1. Toshov, J.B. (2016). The Questions of the Dynamics of Drilling Bit on the Surface of Well Bottom. Archives of Mining Sciences, 61(2), 275-283. https://doi.org/10.1515/amsc-2016-0020

2. Morozov, L.V. (2003) Improving the durability of drill bits based on computer analysis of structural elements and their assembly. PhD Thesis. Samara, Russia: SamGTU.

3. Shigin, A.O., \& Gilyov, A.V. (2012). Metodika rascheta ustalostnoy prochnosti kak osnovnogo faktora stoykosti sharoshechnykh dolot. Vestnik Irkutskogo Gosudarstvennogo Tekhnicheskogo Universiteta, (3), 22-27.

4. Poderni R.Yu. (2001). Gornye mashiny i kompleksy dlya otkrytykh gornykh rabot. Moskva: Moskovskiy gosudarstvennyy universitet, 442.

5. Shigina A.A., Shigin A.O., Stupina A.A. (2012). Sravnitel'naya otsenka metodov analiza effektivnosti funktsionirovaniya burovykh stankov. Sovremennye Problemy Nauki $i$ Obrazovaniya, (6), 117.

6. Mannanov, U., Toshov, J., \& Toshniyozov L. (2019). Perspective Solutions for the Design of $\begin{array}{lllll}\text { Drilling Tools. E3S Web of Conferences, } & (105), & \end{array}$ https://doi.org/10.1051/e3sconf/201910503027

7. Blinkov, O.G., \& Serdyuk N.I. (2017). Germetiziruyushchie ustroystva opor sharoshechnykh dolot dlya vysokooborotnogo bureniya. Territoriya "Neftegaz", (3), 12-16.

8. Toshov, J.B. (2016). Ways towards optimization of washout components of rock cutting tools. Gornyi Zhurnal, (2), 21-24. http://dx.doi.org/10.17580/gzh

9. Karvanen, A.Ye. (2014). Reglament tekhnicheskogo obsluzhivaniya i remonta rolikovykh konusnykh burovykh instrumentov. Molodezh' i nauka-2014. Krasnoyarsk, Russia: Sibirskiy federal'nyy universitet. 
10. Gribennikov, N.V., Boyarskikh, G.A., \& Boyarskikh, I.G. (2013). Sravnitel'naya otsenka predel'nogo sostoyaniya konstruktivnykh elementov nerazbornykh i razbornykh burovykh sharoshechnykh dolot. Izvetiya Ural'skogo Gosudarstvennogo Universiteta, 1(29), 43-55.

11. Toshniyozov L.G., \& Toshov, J.B. (2019). Analiz teoreticheskikh i eksperimental'nykh issledovaniy $\mathrm{v}$ oblasti protsessa sal'nikoobrazovaniya pri burenii skvazhin. Gornyy Informatsionno-Analiticheskiy Byulleten', (11), 139-151. https://doi.org/10.25018/023614932019-11-0-139-151

12. Lu, Z., Wan, L., Zeng, Q., Zhang, X., \& Gao, K. (2017). Numerical Simulation of Fragment Separation during Rock Cutting Using a 3D Dynamic Finite Element Analysis Code. Advances in Materials Science and Engineering 2017, 1-17. https://doi.org/10.1155/2017/3024918

13. Labra, C., Rojek, J., \& Oñate, E. (2016). Discrete/Finite Element Modelling of Rock Cutting with a TBM Disc Cutter. Rock Mechanics and Rock Engineering, 50(3), 621-638. https://doi.org/10.1007/s00603-016-1133-7

14. Huang, K., Ai, Z., \& Yang, Y. (2019). Working characteristics research on the impacting-cutting hybrid bit. Advances in Mechanical Engineering, 11(5), 168781401985094. https://doi.org/10.1177/1687814019850941

15. Jaime, M. C., Zhou, Y., Lin, J.-S., \& Gamwo, I. K. (2015). Finite element modeling of rock cutting and its fragmentation process. International Journal of Rock Mechanics and Mining Sciences, (80), 137-146. https://doi.org/10.1016/j.ijrmms.2015.09.004

16. Pawar, P., Ballav, R., \& Kumar, A. (2017). Modeling and Simulation of Drilling Process in Ti6Al-4V, Al6061 Using Deform-3D Software. International Journal of ChemTech Research, 10(3), 137-142.

17. Gopichand, A., Veera Brahmam, M., Bhanuprakash, D. (2014). Numerical Simulation and Analysis of Friction Drilling Process for Alumina Alloy using Ansys. International Journal of Engineering Research \& Technology, 3(12), 602-607.

18. Abdul-Rani, A.M., Ismail, M.Z., Zaky, M.A., Noor, M.H.M., Zhun, Y.Y., Ganesan, K., ... Ginta, T.L. (2014). Improving Rate of Penetration for PDC Drill Bit Using Reverse Engineering. $\begin{array}{llll}\text { Applied Mechanics and 153-160. } & \text { (607), }\end{array}$ https://doi.org/10.4028/www.scientific.net/amm.607.153 